\title{
EFFICIENT TRANSDUCTION OF DENDRITIC CELLS USING CORONAVIRUS-BASED VECTORS
}

\author{
Klara K. Eriksson, Divine Makia, Reinhard Maier, Luisa Cervantes, \\ Burkhard Ludewig, and Volker Thiel*
}

\section{INTRODUCTION}

Coronavirus-based vectors are currently considered a promising means to deliver multiple heterologous genes to specific target cells. During replication of the coronavirus RNA genome in the host cell cytoplasm, 6-8 subgenomic mRNAs encoding for structural and accessory proteins are produced. Most of these genes can be replaced by heterologous genes without affecting RNA replication. ${ }^{1,2}$ This allows the insertion of more than $6 \mathrm{~kb}$ into coronavirus-based vectors. ${ }^{1-4}$ Replication without a DNA intermediate in the host cell cytoplasm makes insertion of vector-derived sequences into the host cell genome unlikely. This, together with replacement of structural viral genes in the vector by heterologous sequences, makes these noninfectious vectors safe. An important consideration for viral vaccine vectors is the potential to efficiently deliver genetic material to specific target cells. Targeting of viral vaccine vectors to professional antigen-presenting cells, such as dendritic cells (DCs), is highly desirable in order to optimize vaccine efficacy. ${ }^{5,6}$ The receptors of human coronavirus $229 \mathrm{E}$ and mouse hepatitis virus (MHV) are expressed on DCs, ${ }^{7-9}$ indicating that vectors based on these viruses can be used to deliver genetic cargo efficiently to DCs via receptor-mediated transduction. ${ }^{1}$ Therefore, recombinant MHV vectors in the context of a murine model can serve as a paradigm for the development and evaluation of coronavirus vaccine vectors suitable for in vitro and in vivo transduction of human DCs.

To investigate to what extent coronavirus vectors can induce antitumoral and antiviral humoral and cellular immune responses in vivo, we generated vectors based on mouse hepatitis virus to be used for studies of the immunological response to antigens expressed on murine dendritic cells. In these vectors, the structural genes encoding the viral envelope (E) and membrane (M) proteins have been deleted and replaced by sequences encoding a reporter protein (green fluorescent protein [GFP]) fused to an

*Kantonal Hospital St.Gallen, 9007 St.Gallen, Switzerland. 
immunogenic epitope (e.g., LCMV gp33). We generated packaging cells stably expressing MHV E and M proteins and transfected MHV vector RNA into these by electroporation. Vector RNA-transfected packaging cells replicated and transcribed recombinant vector RNA as shown by reporter gene expression and syncytia formation in cell cultures. Vector RNA was packaged into viral-like particles as shown by transduction of dendritic cells after transfer of cell culture supernatants from vector transfected packaging cells. Further studies will address activation and antigen presentation of vector-transduced dendritic cells in a mouse model. Stable integration in packaging cells of the sequence encoding either MHV S, or of a chimeric S protein that will give vector particles the ability to transduce human dendritic cells, will further improve the applicability of these packaging cell lines for production of vectors for immunotherapeutical studies.

\section{RESULTS}

\subsection{MHV Vector RNA Structure}

We have previously established a reverse genetic system based on full-length cDNA copies of coronavirus genomes cloned and propagated in vaccinia virus. ${ }^{10-12}$ Based on this system we have constructed a cDNA encoding a MHV prototype vector RNA using vaccinia virus-mediated homologous recombination. As illustrated in Figure 1, the vector RNA encodes the MHV 5'- and 3'- non-translated regions, the MHV replicase, spike and nucleocapsid genes. Furthermore, we inserted a reporter gene encoding a fusion protein comprised of GFP fused to an immunogenic epitope (e.g., LCMV gp33). The MHV vector RNA can be produced by in vitro transcription from genomic DNA of the recombinant vaccinia virus.

\subsection{Generation of Packaging Cell Lines}

In order to package MHV vector RNAs, we established a packaging cell line expressing MHV structural proteins E and M. These cells are based on 17 clone-1 cells that are susceptible to MHV infection. ${ }^{13,14}$ Genes encoding MHV E and M proteins were cloned downstream of a SV40 and CMV promoter, respectively, in a plasmid DNA conferring neomycin resistance. Using G418 selection we could obtain several stable cell clones that were analyzed for $\mathrm{E}$ and $\mathrm{M}$ protein expression. First, genomic DNA was

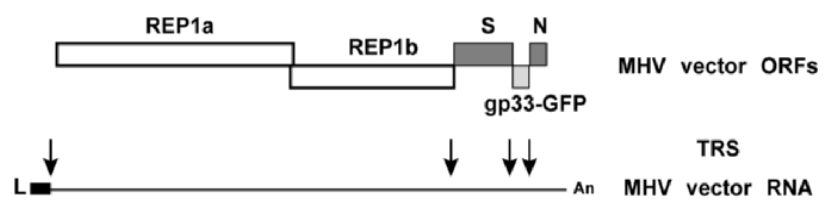

Figure 1. MHV vector RNA structure. The structure of the MHV vector RNA is illustrated. Open reading frames are indicated as boxes designated by encoded gene products. L, leader RNA; An, synthetic poly(A) tail. Transcription regulatory sequences (TRS) proceed each gene and are indicated as arrows. 

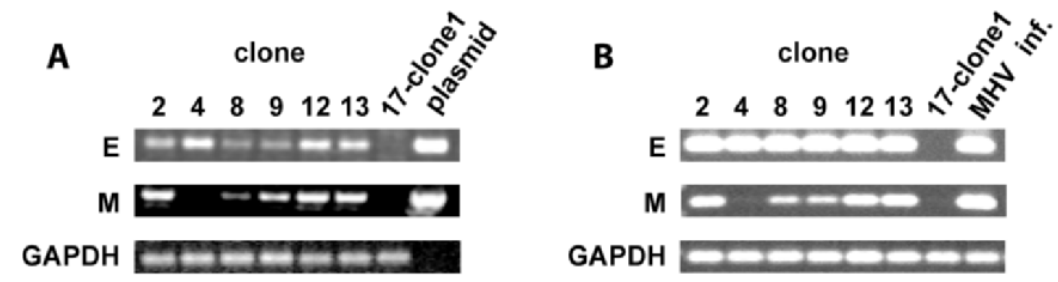

Figure 2. Analysis of packaging cell lines. Plasmids encoding MHV structural proteins $\mathrm{E}$ and $\mathrm{M}$ were transfected into 17-clonel cells. Individual stable clones were selected and analyzed for $\mathrm{E}$ and $\mathrm{M}$ expression by PCR using genomic DNA as template (A) and RT-PCR using poly(A)-containing RNA as template (B).

isolated, and PCR was performed to verify integration of the E and M-encoding genes (Fig. 2a). Then, poly-A containing RNA was isolated as described ${ }^{17}$ and oligo-dT-primed reverse transcription (RT) reactions followed by PCR were performed to verify expression of the E and $\mathrm{M}$ transcripts (Fig. 2b). Finally, E and M protein expression was confirmed by immunofluorescence analysis using E- and M-specific antisera (data not shown).

\subsection{Generation of Vector RNA-Containing VLPs and Transduction of Murine DCs}

After transfection of the MHV vector RNA into E and M protein-expressing packaging cells, the cells were monitored by fluorescence microscopy. After $24 \mathrm{~h}$ green fluorescent syncytia and plaques became apparent (Fig. 3b, left panel). To test whether VLPs have been formed and whether these particles are capable of transducing murine dendritic cells (DCs), we transferred tissue culture supernatant of MHV vector RNAtransfected packaging cells to murine DCs. After $12 \mathrm{~h}$ green fluorescent DCs were

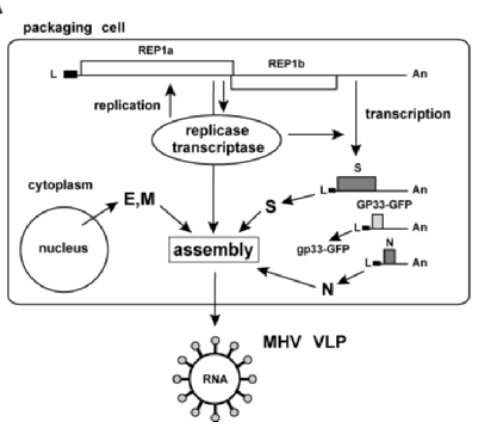

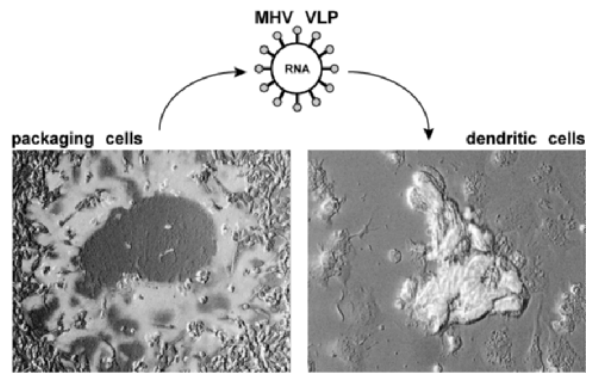

Figure 3. Generation of vector RNA-containing VLPs and transduction of murine DCs. The strategy for the production of MHV vector RNA-containing VLPs is illustrated (A). Green fluorescent syncytia and plaques were detected in vector RNA-transfected packaging cells (B, left panel). Bone marrow-derived murine DCs were cultured with supernatant from vector RNA-transfected packaging cells. Green fluorescent DCs became apparent within $24 \mathrm{~h}(\mathrm{~B}$, right panel). 
detectable (Fig. 3b, right panel). Therefore, we conclude that VLPs containing MHV vector RNAs have been formed in packaging cells and that these VLPs can be used to transduce murine DCs.

\section{ACKNOWLEDGMENTS}

This work was supported by the Gebert-Rüf Foundation, The Swiss Cancer League, and the UBS Optimus Foundation, Switzerland.

\section{REFERENCES}

1. V. Thiel, N. Karl, B. Schelle, P. Disterer, I. Klagge, and S. G. Siddell, Multigene RNA vector based on coronavirus transcription, J. Virol. 77, 9790-9798 (2003).

2. V. Thiel, J. Herold, B. Schelle, and S. G. Siddell, Viral replicase gene products suffice for coronavirus discontinuous transcription, J.Virol. 75, 6676-6681 (2001).

3. P. J. Bredenbeek and C. M. Rice, Animal RNA virus expression systems, Semin Virol 3, 297-310 (1992).

4. L. Enjuanes, I. Sola, F. Almazan, et al., Coronavirus derived expression systems, J. Biotechnol. 88, $183-$ 204 (2001).

5. R. M. Steinman and M. Pope, Exploiting dendritic cells to improve vaccine efficacy, J. Clin. Invest. 109, $1519-1526(2002)$

6. W. Lu, X. Wu, Y. Lu, W. Guo, and J. M. Andrieu, Therapeutic dendritic-cell vaccine for simian AIDS, Nat. Med. 9, 27-32 (2003).

7. C. L. Yeager, R. A. Ashmun, R. K. Williams, C. B. Cardellichio, L. H. Shapiro, A. T. Look, and K. V. Holmes, Human aminopeptidase $\mathrm{N}$ is a receptor for human coronavirus 229E, Nature 357, 420-422 (1992).

8. R. Thomas, L. S. Davis, and P. E. Lipsky, Isolation and characterization of human peripheral blood dendritic cells, J. Immunol. 150, 821-34 (1993).

9. B. C. Turner, E. M. Hemmila, N. Beauchemin, and K. V. Holmes, Receptor-dependent coronavirusinfection of dendritic cells, J. Virol. 78, 5486-5490 (2004).

10. V. Thiel, J. Herold, B. Schelle, and S. G. Siddell, Infectious RNA transcribed in vitro from a cDNA copy of the human coronavirus genome cloned in vaccinia virus, J. Gen. Virol. 82, 1273-1281 (2001).

11. V. Thiel and S. G. Siddell, Reverse genetics of coronaviruses using vaccinia virus vectors, Curr. Top. Microbiol. Immunol. 287, 199-227 (2005).

12. S. E. Coley, E. Lavy, S. G. Sawicki, L. Fu, B. Schelle, N. Karl, S. G. Siddell, and V. Thiel, Recombinant mouse hepatitis virus strain A59 from cloned, full-length cDNA replicates to high titers in vitro and is fully pathogenic in vivo, J. Virol. 79, 3097-3106 (2005). 